\title{
An Electronic Collaborative Learning Environment for Standardized Tests
}

\author{
Sultan Alyahya and Asma Aldausari \\ Department of Information Systems, King Saud University, Saudi Arabia \\ sualyahya@ksu.edu.sa
}

\begin{abstract}
The National Center for Measurement (Qiyas) was established for the purpose of conducting standardized tests in Saudi Arabia. The center has developed multiple Qiyas tests such as the General Aptitude Test (GAT) and the Scholastic Achievement Admission Test (SAAT). Qiyas tests are used as a pre-requisite requirement for applying to universities and to certain kinds of jobs in Saudi Arabia. Currently, students use traditional methods to prepare for these tests, e.g., studying from books and searching for available learning resources on the internet. These web-based resources are mostly static and only have general guidelines about the tests and a history of available test samples. This research proposes a computerbased collaborative learning $(\mathrm{CL})$ environment that helps support learners during their preparation for the Qiyas tests. A four-stage approach is used in this research: (1) an intensive review of $30 \mathrm{CL}$ platforms is carried out to investigate the available features, (2) two workshops are conducted to evaluate the appropriateness of the features identified in Stage 1 as well as to investigate what other features would be appropriate for Qiyas tests, (3) a CL platform is developed for Qiyas tests for a total of 21 features, (4) and, lastly, the platform is evaluated using two methods, in-depth interviews with experts and an empirical study with instructors and learners. The results show that the platform helps support learners in the participative, cognitive, interactive, and social dimensions of the learning processes. The results also help instructors promote the teaching experience.
\end{abstract}

Keywords: E-Learning, Collaborative Learning, Qiyas, Standardized Tests, Evaluation

\section{Introduction}

The National Center for Measurement (Qiyas) was established in 2001 for the purpose of conducting standardized tests in Saudi Arabia (National Center for Assessment, 2019). The center has developed multiple Qiyas tests such as the General Aptitude Test (GAT) and the Scholastic Achievement Admission Test (SAAT). In Saudi Arabia, Qiyas tests are used as a pre-requisite requirement for applying to universities and to certain kinds of jobs. For example, students are required to take the GAT and SAAT before seeking admission to Saudi universities (Hendrickson, 2012). A combination of student scores on these tests along with their high school GPA are used to generate a single score for each candidate, and this determines the individual competency for admission. Many local universities give a weight of 70\% for Qiyas tests (Alnahdi, 2015; Bajammal et al., 2008).

Approximately 90 s\% of university students believe they did not receive adequate preparation before taking the tests (Kaki and Alaskar, 2014). Currently, students use traditional methods to prepare for the tests, e.g., studying from books and searching for available learning resources on the internet (Almajed, 2010). These web-based resources are mostly static and have just general guidelines about the tests and a history of available test samples (Almajed, 2010). Using these web-based resources, students are more likely to just be passively "reading online" rather than learning or creating knowledge actively online (Lin and Kuo, 2005). Since they are published on the website of the National Center for Assessment, the test results are not viewed as satisfying (Qiyas Statistics and Data, 2019). Consequently, there have been many calls to provide more advanced learning methods for the Qiyas tests (e.g., Ghazi, 2018; Al-Ozaizy, 2016).

Several studies encourage the use of the Collaborative Learning (CL) style (e.g. Bennett, 2004; Lin, 2015). A collaborative learning approach provides an environment that enlivens and enriches the learning process where learners can interact with one or more collaborating peers to solve a given problem (Bennett, 2004). Moreover, those using collaborative learning can construct knowledge in a collaborative learning system by actively interacting with each other through the process of searching for, understanding, negotiating, and finding solutions, etc. (Lin, 2015).

A study conducted by Thompson and Ku (2006) has shown that there is a relation between the degree of collaboration and the quality of learning. In addition, $\mathrm{CL}$ has been used in many fields such as medical education and the results show that the performance of students have improved (Bow et al., 2013). 
The rise of the Internet over the last few decades has enabled learners to work collaboratively from different locations (Kimball, 2001; Bennett, 2004). Online collaborative learning has many key benefits, e.g., it gives learners the opportunities to have an exposure to differing opinions, perspectives, and experiences while providing interactive opportunities with other learners. It also permits learners to move out from their private world and create a shared understanding of meaning (Luo, 2013).

Keeping this in mind, this research proposes a computer-based collaborative learning environment. The proposed platform would enhance the learning experience of users and help support learners during their preparation for Qiyas tests. Although there are currently many platforms that make use of the collaborative learning approach, they are general-purpose platforms and are not designed particularly for Qiyas tests. Moreover, it is unlikely that a single platform could provide all of the features appropriate for those preparing for the Qiyas tests. In addition, those preparing for the Qiyas tests might suggest other favorite collaborative features that have not been developed for any current platform.

The rest of this paper is divided as follows: Section 2 provides an overview of the research related to this work. Section 3 describe the approach we take, and the four components of this approach are described in sections 4 , 5,6 , and 7 . Finally, Section 8 concludes the paper.

\section{Related Work}

\subsection{Collaborative Learning (CL)}

The concept of Collaborative Learning (CL) was coined in the 1950s and 1960s by a group of British secondary school teachers and researchers (Bruffee, 2006; Zahirović et al., 2019). Smith et al. (1992) define CL as an umbrella term for a variety of educational approaches involving a joint intellectual effort to be made by students on their own or by students and teachers together. Usually, students work in groups of two or more and mutually search for understanding, solutions, or meanings, or work to create a product (Smith et al., 1992).

Johnson et al. (1990) note that $\mathrm{CL}$ is not simply having a group of students work together. It must include five basic elements as follows:

- Clear interdependence: team members must rely on each other to achieve a goal. The team will suffer if any member fails to do his or her part.

- Considerable amount of interaction: members should support and help each other to learn by gathering and sharing knowledge.

- Personal responsibility: all members of the group are obliged to do their work.

- Social skills: team members gain leadership, decision-making, communication, and conflict management skills through group work.

- Group self-evaluation: team members should point out the goals in order to evaluate the group periodically.

In the past, due to difficulties in finding time and space for students to work together, collaborative learning activities have been restricted to full-time students in on-campus environments (Kimball, 2001). Today, education has been transformed for both teachers and learners due to a rise in Internet-based communication technologies (Bennett, 2004), which has resulted in the rise of Online Collaborative Learning (OCL). Harris (2001) defines online collaboration as an educational endeavor that involves people in different locations using Internet-based tools and resources in order to work together.

A case study conducted by Zhu (2012) indicates that OCL can enhance student knowledge construction through group interactions. Bow et al. (2013) used a collaborative model for creating study tools for preclinical medical education. All through the preclinical course, the medical students must recall massive amounts of information within a limited time, then they should be able to recall this information for the exam. They also need this information for when they are making diagnostic decisions. The results show that students who actively participate in the content while studying attain a higher score on the exam.

Benbunan-Fich, Hiltz, and Harasim (2004) explained that in order to have successful OCL learning outcomes, the following input and process factors need to be considered. The input factors are technology, the students, the instructor, and the course. The technology factor includes technical terms such as functionality, usability, and synchronous and asynchronous communication modes. The student factor is described by the degree of 
motivation, cognitive ability, and learning style. The instructor factor is identified by the teachers' actions and experiences in online teaching. The course factor is characterized by the number of students involved, the organization of the group, the size of the group, and the type of group leadership. The process factor highlights the mode of the learning processes as well as the amount and types of activities or interactions.

\subsection{Qiyas Tests}

Qiyas tests are measurements that are offered by the National Center for Assessment in Saudi Arabia. The center develops multiple tests under the following categories: educational tests, language tests, and vocational tests. The educational tests include the General Aptitude Test (GAT) (which is provided in both English and Arabic), the Scholastic Achievement Admission test (SAAT), the Post-Graduate Aptitude Test, and a variety of educational attainment tests (National Center for Assessment, 2019). Among these, the GAT is considered to be the most important educational test (Kaki and Alaskar, 2014). This is a standardized measurement that consists of two sections: verbal and quantitative. The abilities tested in the GAT include reading comprehension, the recognition of logical relations, problem solving using mathematics, inference, and measuring capacity (National Center for Assessment, 2019; Sulphey, Al Kahtani and Syed, 2018). The second most important educational test is the SAAT, which is used as a requirement for admission to science and health colleges (Sulphey, AlKahtani and Syed, 2018) and examines student skills with regard to the knowledge they learned in high school through questions developed from the content of school books (Al-Owidha, 2013; Alnahdi, 2015; Khoshaim, 2017).

Language tests are another type of assessment that is provided by the center. The center provides the Standardized Test for English proficiency (STEP) as well as an Arabic language test for non-native speakers. Moreover, the center has developed vocational tests such as a teachers test, the Saudi council of engineers exam, and an educational supervision test (National Center for Assessment, 2019).

The online collaborative learning support currently used for Qiyas tests is limited. Our review shows that there are only two platforms that support learners who are preparing for Qiyas tests. These are described below along with their main functionalities.

\section{Noon Academy:}

This is an online learning platform implemented in 2016. It provides learners with information and recourses. The following list includes the main functions provided by the Noon Academy:

- Practice tests: the platform provides multiple samples of exams that learners can take to practice and improve their skills before taking the real exam.

- The lessons: each lesson consists of two sections. The first section includes multiple flashcards to explain the theories and to provide simple examples. The second section includes multiple choice questions. Once the learner submits his or her answer, the platform will provide the learner with the correct answer and a simple explanation immediately.

- Group session: this function provides learners with the ability to select a lesson. After doing this, the learner can share the invitation link with friends. After that, the learner can select a teacher and wait for the lesson to begin.

The content is managed and updated by the Noon Academy only. For this reason, the content is for the most part not up to date. If a learner has a question, he or she needs to open a group session with a minimum of five learners in order to get help from the teachers or other learners.

\section{The Initialization and Training Program prepared by Qiyas:}

This is an online learning platform that aims to train learners for the GAT and SAAT before taking the tests. The platform includes three training types as listed below:

- The first training type teaches scientific concepts. In this section, the basic concepts are explained in an attractive and interactive way by using Adobe Flash.

- The second training type provides the learner with three practice tests and the platform provides learners with automatic feedback regarding the correct answer.

- The last type includes experimental tests. These tests allow learners to evaluate his or her level. Once the learner finishes the experimental test, the platform will provide the learner with his or her grade. 
The content for this platform is managed by Qiyas and therefore the content is fixed. In addition, the platform does not provide for any kind of active learning experience through discussions, collaboration, or critical thinking and joint problem-solving.

\section{Approach}

The aim of this research is to develop a computer-based collaborative learning environment that supports learners during their preparation for Qiyas tests. This aim is achieved by following these four stages:

Stage 1: Reviewing CL platforms: by reviewing CL tools, we explore the commonly used functions of collaborative learning environments. This helps us to understand the nature of the functions that should be provided. In order to achieve this goal, a total of 30 tools have been reviewed, which resulted in our identifying 23 potential features (F1, F2 ... F23).

Stage 2: Determining the appropriate features: two workshops are conducted in this stage. The main purpose of the workshops is to discuss the extracted features from Stage 1 with the workshops' participants in order to obtain their opinions. Another purpose is to check if they have any other favorite collaborative features that were not discovered during the review of the existing collaborative platforms.

Stage 3: Developing a CL platform for Qiyas tests: a web-based system has been developed. This system includes all of the features identified by the learners participating in Stage 2.

Stage 4: Final evaluation: after implementing the system, we conducted a final evaluation for the system using two methods: in-depth interviews with experts and an empirical study with instructors and learners.

\section{Stage 1: Reviewing CL platforms}

This section reviews a number of selected collaborative learning platforms. Thirty selected platforms are reviewed in order to analyze the most commonly used collaborative learning features. The list of tools includes the most recommended platforms, which is based on the Best MOOC Platforms (2018). A detailed features matrix of the selected collaborative learning platforms is provided in Table 1 and described below.

\section{F1: Create a User Profile}

All the surveyed platforms require a user registration and the creation of a user profile. Usually, the profile page contains the basic information about the user such as name, educational level, country, role, and enrolled courses. Moreover, some platforms such as Maharah, Eliademy, and Simpliv allow the user to link his or her account with the social media accounts such as LinkedIn, Facebook, and Twitter. Rwaq enables users to add and share their resumes. Some tools, such as Coursera and Udacity, provide profiles of course providers.

F2: Changing the User Profile to Private Mode

Changing the user profile to private mode has different meanings. In some platforms, like Future Learn, there are two options. First, the user can make his or her profile partially private. Only learners who are signed into the platform can see the profile. Second, the user can make his or her profile completely private. In this case, even other learners on the site will not be able to see the profile. The Codeacademy platform provides two options: allowing other Codeacademy users to view the profile or allowing everyone to view the profile. Rwaq allows a user to make his or her profile page publicly available only for the instructors of the courses that the user is taking or for everyone. Coursera has a list of three options: allowing only the user, only the Coursera community, or everyone on the web to view the profile.

\section{F3: Providing a General Discussion Forum}

A discussion forum, such as one found in Simplilearn and Codecademy, is known by a variety of names, such as community in the DataCamp platform. A discussion forum is a general term for a place where users can leave messages or questions and expect to see responses from other users. Moreover, a discussion forum is a place in which people can exchange ideas and discuss issues not related to any course. Therefore, users can post general questions. On some platforms such as Cognitive Class and Eliademy, the discussion forum includes two sections: contact support and give feedback. Users can post in both sections and receive responses from either other users or from the platform's team. 
F4: Send Private Messages to Instructors and Other Learners The private message (i.e. or direct message) is a type of message that is sent between different members on a given platform. It can only be seen and accessed by the users who are participating in the message. Many $\mathrm{CL}$ platforms allow learners to send private messages through the platform to instructors. Edlal and iversity allows a learner to send a message to other learners as well.

\section{F5: Enroll in a Course}

Most platforms enable users to enroll in courses. They can be free or need to be paid for.

\section{F6: Award Points/Badges to indicate Active and Collaborative Learners}

Most of the CL platforms support making a distinction between active and non-active learners through the use of award points or badges. To indicate an active learner, some platforms such as DataCamp count the number of courses completed and the number of the solved exercises. Other platforms such as Khan Academy and Cognitive Class use badges to indicate the collaborative learners. For example, on the Khan Academy platform, there is a badge if a learner posts 100 answers that have three votes each. There is also another badge for achieving mastery points in the course. For Future Learn, the "follow" feature is used to indicate collaborative learners. In this case, the active learner will have a higher number of followers. On the Openlearning platform, learners receive kudos points if they contribute a high quality level of content via comments that might be helpful and informative for other people.

\section{F7: Sharing the Learners' Success Stories}

In order to motivate other learners to register on the platform and enroll in the courses, some collaborative platforms share the success stories of their learners. A story could include a picture, video, audio, or text. This feature is supported by some selected collaborative platforms such as Codecademy. In this platform, a learner can share his or her success story using a video or text. Also, this feature is available for Jigsaw Academy, Lynda, IntelliPaat, Eliademy, Edureka, Teamie, and Alison.

\section{F8: Sharing Courses on Social Media}

Some collaborative learning platforms such as the Canvas Network allow learners to share the courses they are enrolled-in on social media sites such as Facebook, Twitter, and LinkedIn. This feature facilitates the ability to increase the number of new learners. On the Future Learn platform, there is a section under each course with the title "Do you know someone who'd love this course? Tell them about it." In this section, a learner can share the course on social media. On the Skillshare platform, a learner can earn one free month for each friend who signs up.

\section{F9: Like or Follow Other Learners' Posts}

This is an important social feature that is supported by most of the selected collaborative platforms. Using this feature, a learner is encouraged and motivated to add his or her rich and helpful posts. On the Open2Study, Edraak, and Khan Academy platforms, in order to indicate the important posts, a learner can increase the number of votes. On the Future Learn platform, a learner can like, follow, or bookmark other learners' posts. The iversity, Rwaq, Maharah, and Openlearning platforms have only the "like" feature for other learners' posts. The SkillShare, edX, and Coursera platforms have like (or upvotes) and follow thread features. The Udemy platform allows a learner to follow other learners' posts only. The Alison platform permits learners to provide a thumb up or thumb down for other learners' posts.

F10: Classify Courses

Most collaborative learning platforms classify their courses under specific categories in order to make them easier to find.

\section{F11: Create Courses by Instructor}

On some collaborative learning platforms, only a specific user such as an instructor or an author can create a course and upload content. The instructor can upload a variety of types of files, e.g. documents, images, videos, and audio files. When the platform applies this feature, this means that their content will be reliable and there is no need for a verification step before publishing the course on the platform. 
F12: Create Courses by any User

For Maharah, Eliademy, and Google Classroom, every user can create a course and upload content. In these cases, the verification step is mandatory.

F13: Display Course Details

The course details are available for learners who wish to get a comprehensive view of the course. For each course, the following information should be shown: instructor details, course topics, course description, prerequisites, output of the course, suggested references, etc.

F14: Provide a certificate

Some collaborative learning platforms provide the learner with a certificate when he or she passes the course. This feature can encourage the learner to study and complete the course. On the DataCamp platform, when a learner completes a course, the learner will receive a statement of accomplishment that can be downloaded or shared on Linkedin.

F15: Add Announcements

Most CL platforms dedicate a single section for each course to show the announcements that are posted by the instructor. This feature allows the learner to find the important posts from the instructor easily.

\section{F16: Receive Notifications}

Most CL platforms support the notification feature and have a special icon where a user can access the notification page. From the account settings, users can customize notifications (i.e., determine the types of events that he or she is notified about).

\section{F17: Send/Receive Email Messages}

On some platforms, the user can send and receive emails to and from instructors, learners, or the platform administrative. Users are allowed to customize and turn on/off emails.

F18: Post a Question and Add a Reply

Many CL platforms support and encourage learners to post their questions. When a question is asked, other learners for the same course or the course instructor are able to answer.

F19: Add an Anonymous Post

Sometimes people feel more comfortable initiating discussions anonymously in these courses. This feature is supported and used on some collaborative platforms such as edX and Edraak.

\section{F20: Review and Rate Courses}

Usually, learners check other learners' reviews and ratings before enrolling in any course. Based on this, most collaborative learning platforms support allowing learners to select a rating level (usually on a five-star scale) and to give a review. On some platforms such as the Khan Academy, there is a "thanks" tab under each course. Using this tab, learners can post their reviews and comments about the course.

F21: Show Learners' Progress in the Online Learning Process

Some platforms provide learners with a dashboard that they can use to check their progress in the learning process.

F22: Show Number of Participants in a Course

Some platforms show the total number of people who participate in a course. This feature may encourage other learners to enroll in the same course.

F23: Showing the Number of Courses and Registered Learners

Some platforms such as Tamkeen, Alison, and New Skills Academy display a dashboard on the home page that displays the total number of learners, courses, and lessons. Other platforms such as Lynda, edX, and Rwaq display only the total number of courses under each course category. 


\section{Stage 2: Determining the Appropriate Features}

Two workshops were conducted during this stage (i) to evaluate the appropriateness of the features identified in Stage 1, and (ii) to investigate what other features might be appropriate for the Qiyas tests. We followed the instructions for conducting workshops as identified by Tiberius and Silver (2001). The instructions include guidelines such as that participants should be in a small group and that they should involve people who have real experience in the subject under discussion.

The participants have completed various types of Qiyas tests. The first workshop included seven persons, all of whom had taken the STEP and Post-Graduate General Aptitude Test. The second workshop included nine persons, seven of whom had taken the GAT and SAAT tests and two of whom had taken the Educational Supervision Test. For both workshops, a PowerPoint presentation was used to explain the current features more clearly.

The following list shows the features that were suggested by the workshop's participants and were not already discovered during Stage 1:

\section{F 24: Vote for Offering a Course}

Workshop participants suggested that we add course voting. This would allow learners to vote for the courses that are needed and can be created by the instructors. Therefore, the instructors would check this information before creating any new course.

\section{F 25: Add Lessons into Course}

The participants suggested dividing each course into separate lessons. They believe that this partitioning will help learners to better understand the courses and also help them to focus on the lessons they particularly need to study more.

F 26: Provide a Question Bank

The participants suggested adding a question bank. When a learner takes any of the Qiyas tests, the learner can then share the questions by posting them in the question bank along with the correct answer.

\section{F 27: Approve an Answer}

The participants asked that we add a tag to identify the correct answer for a question that is written by a learner. Instructors would have the ability to approve the answers.

F 28: Complete a lesson

The participants suggested that we also add a button that says "complete a lesson." A learner would click on this button once he or she understood a lesson well.

Table 2 and Figure 1 below illustrate the number of workshop participants who agreed, disagreed, or were undecided about each collaborative feature. The list includes their votes for the 23 features identified in Stage 1 as well as the seven new features. Although some features were mentioned first by the participants in one workshop and were not mentioned by the other, we asked everyone in both workshops whether or not they agree that these features are worth adding into a CL environment for Qiyas tests. We have applied the $50 \%$ Rule to determine which features should be supported by our proposed system. This means that if at least $50 \%$ of the respondents are in the support of an opinion, then that opinion should be accepted. This method has been followed by other researchers (Alyahya and Alsayyari, 2020; Rainer and Hall, 2002; Niazi, Wilson and Zowghi, 2005; Cox, Niazi and Verner, 2009). As a result, 21 features were picked and seven features were eliminated (F2, $F 7, F 12, F 14, F 17, F 19$, and F23). 
Table 1: Detailed Features Matrix of the Selected Collaborative Learning Platforms (a highlighted cell indicates that the platform supports the feature).

\begin{tabular}{|c|c|c|c|c|c|c|c|c|c|c|c|c|c|c|c|c|c|c|c|c|c|c|c|}
\hline \multirow{2}{*}{ C. Platforms } & \multicolumn{23}{|c|}{ Features } \\
\hline & $F_{1}$ & $F_{2}$ & $F_{3}$ & $\mathrm{~F} 4$ & $\mathrm{F5}$ & $F_{6}$ & F7 & $F 8$ & $\mathrm{F9}$ & $F_{10}$ & $F 11$ & $F 12$ & $F 13$ & F14 & $F_{15}$ & $F_{16}$ & $F 17$ & $F 18$ & $\mathrm{~F} 19$ & $\mathrm{~F} 20$ & $F 21$ & $\mathrm{~F} 22$ & $F 23$ \\
\hline \multirow{2}{*}{\multicolumn{24}{|c|}{$\begin{array}{c}\text { DataCamp } \\
\text { Google }\end{array}$}} \\
\hline & & & & & & & & & & & & & & & & & & & & \multicolumn{4}{|c|}{ Classroom } \\
\hline \multicolumn{24}{|l|}{ Teamie } \\
\hline \multicolumn{24}{|l|}{ Rwaq } \\
\hline \multicolumn{24}{|l|}{ Maharah } \\
\hline \multirow{2}{*}{\multicolumn{24}{|c|}{$\begin{array}{l}\text { Simpliv } \\
\text { Edraak }\end{array}$}} \\
\hline \multirow{2}{*}{\multicolumn{24}{|c|}{$\begin{array}{l}\text { Edraak } \\
\text { Tamkeen }\end{array}$}} \\
\hline & & & & & & & & & & & & & & & & & & & & & & & \\
\hline \multicolumn{24}{|l|}{ edX } \\
\hline \multirow{2}{*}{\multicolumn{24}{|c|}{$\begin{array}{l}\text { Udemy } \\
\text { Udacity }\end{array}$}} \\
\hline & & & & & & & & & & & & & & & & & & & & & & & \\
\hline \multicolumn{24}{|l|}{$\begin{array}{l}\text { New Skills } \\
\text { Academy }\end{array}$} \\
\hline \multicolumn{24}{|l|}{ Coursera } \\
\hline \multicolumn{24}{|l|}{$\begin{array}{c}\text { Khan } \\
\text { Accademy }\end{array}$} \\
\hline \multicolumn{24}{|l|}{$\begin{array}{c}\text { Canvas } \\
\text { Network } \\
\end{array}$} \\
\hline \multicolumn{24}{|l|}{ Future Learn } \\
\hline \multicolumn{24}{|l|}{$\begin{array}{c}\text { Cognitive } \\
\text { Class }\end{array}$} \\
\hline \multicolumn{24}{|l|}{ iversity } \\
\hline \multicolumn{24}{|l|}{ openlearning } \\
\hline \multicolumn{24}{|l|}{ Alison } \\
\hline \multirow{2}{*}{\multicolumn{24}{|c|}{$\begin{array}{c}\text { Skillshare } \\
\text { Jigsaw }\end{array}$}} \\
\hline & & & & & & & & & & & & & & & & & & & & & & & \\
\hline Edureka & & & & & & & & & & & & & & & & & & & & & & & \\
\hline Eliademy & & & & & & & & & & & & & & & & & & & & & & & \\
\hline Simplilearn & & & & & & & & & & & & & & & & & & & & & & & \\
\hline Codecademy & & & & & & & & & & & & & & & & & & & & & & & \\
\hline Lynda & & & & & & & & & & & & & & & & & & & & & & & \\
\hline IntelliPaat & & & & & & & & & & & & & & & & & & & & & & & \\
\hline Open2Study & & & & & & & & & & & & & & & & & & & & & & & \\
\hline Edlal & & & & & & & & & & & & & & & & & & & & & & & \\
\hline
\end{tabular}

Table 2: Results of workshop participants' opinions (the highlighted feature indicates that it is not selected)

\begin{tabular}{|c|l|c|c|c|}
\hline No. & \multicolumn{1}{|c|}{ Feature } & Agree & Disagree & Undecided \\
\hline F1 & Create user profile & 15 & 0 & 1 \\
\hline F2 & Change user profile to private mode & 5 & 7 & 4 \\
\hline F3 & Provide general discussion forum & 13 & 0 & 3 \\
\hline F4 & Send private message to instructors and other learners & 11 & 3 & 2 \\
\hline F5 & Enroll in a course & 14 & 1 & 1 \\
\hline F6 & Award points/badges to indicate active and collaborative learners & 14 & 0 & 2 \\
\hline F7 & Share the learners' success stories & 5 & 7 & 4 \\
\hline F8 & Share course in social media & 16 & 0 & 0 \\
\hline F9 & Like or follow other learners' posts & 16 & 0 & 0 \\
\hline F10 & Classify courses & 14 & 1 & 1 \\
\hline F11 & Create course by instructor & 16 & 0 & 0 \\
\hline F12 & Create course by any user & 7 & 9 & 0 \\
\hline F13 & Display course details & 16 & 0 & 0 \\
\hline F14 & Provide a certificate & 4 & 8 & 4 \\
\hline F15 & Add announcements & 15 & 0 & 1 \\
\hline F16 & Receive notifications & 15 & 0 & 1 \\
\hline F17 & Send/Receive email messages & 6 & 8 & 2 \\
\hline F18 & Post a question and add a reply & 16 & 0 & 0 \\
\hline F19 & Add an anonymous post & 3 & 8 & 5 \\
\hline F20 & Review and rate courses & 13 & 1 & 2 \\
\hline F21 & Show learner progress in online learning process & 14 & 2 & 0 \\
\hline F22 & Show number of participants in a course & 16 & 0 & 0 \\
\hline F23 & Show number of courses and registered learners & 6 & 9 & 1 \\
\hline F24 & Vote for offering a course & 13 & 1 & 2 \\
\hline & & & \\
\hline
\end{tabular}




\begin{tabular}{|c|l|c|c|c|}
\hline No. & \multicolumn{1}{|c|}{ Feature } & Agree & Disagree & Undecided \\
\hline F25 & Add lessons into course & 13 & 2 & 1 \\
\hline F26 & Provide Question Bank & 16 & 0 & 0 \\
\hline F27 & Approve an answer & 16 & 0 & 0 \\
\hline F28 & Complete a lesson & 14 & 1 & 1 \\
\hline
\end{tabular}

\section{Stage 3: Developing a CL Platform for Qiyas Tests}

This section proposes a $\mathrm{CL}$ platform. The design was made using the activity diagrams that represent system processes. An activity diagram is one of the UML diagrams that is used to model the possible behavior of a system. It consists of the detailed activities that make up the features. It is also used to understand the workflow of an object or component in order to help visualize the interactions among different actors (Lethbridge and Laganière, 2004). At an early stage of developing the design, we involved workshop participants in order to make sure that the design was reflecting user preferences.

Table 3 shows the developed system processes and what features are covered for each process. All of the features determined during Stage 2 are covered except for F8, "share course in social media," which was deemed simple and which could be implemented directly using ready APIs.

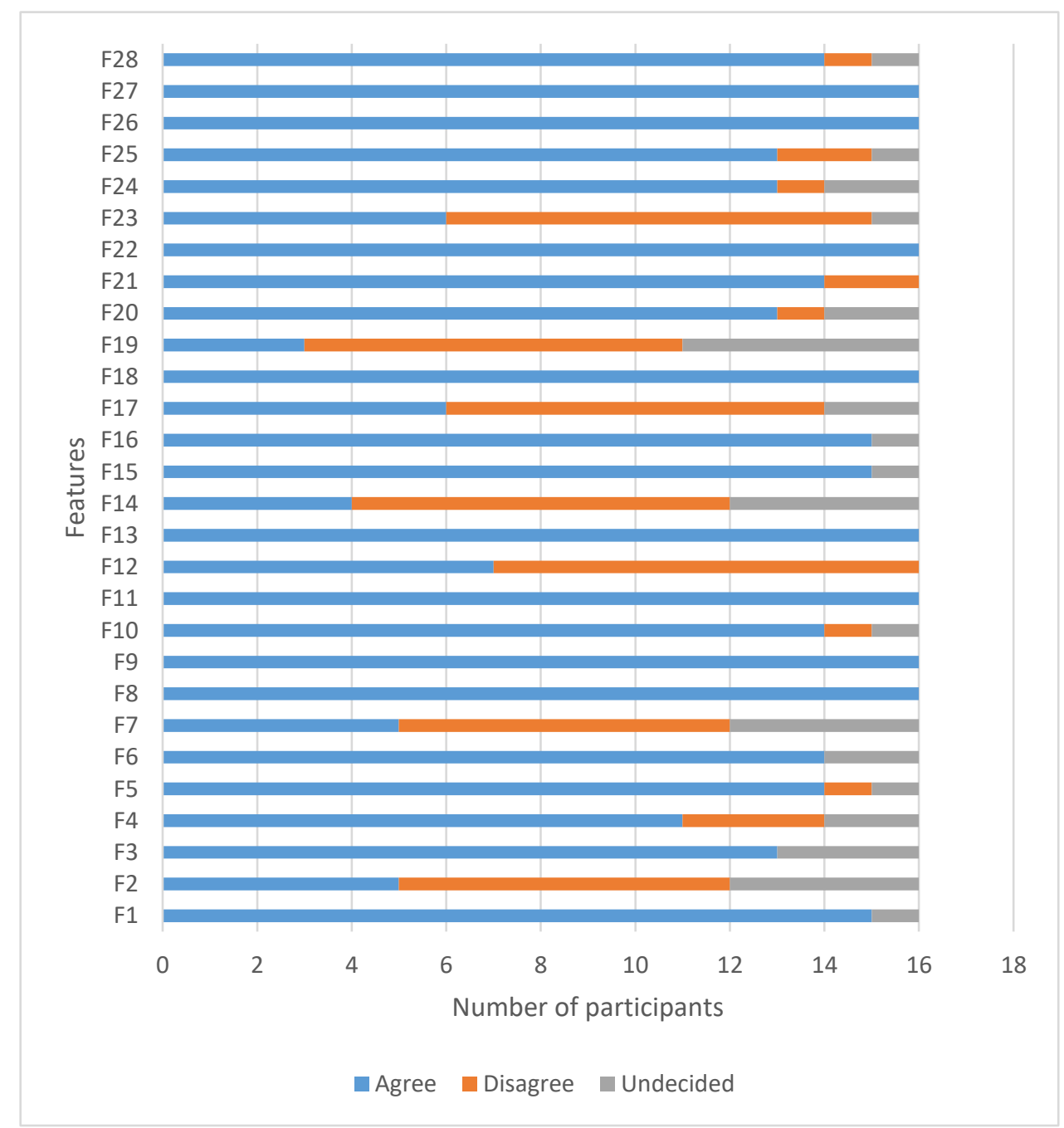

Figure 1: Histogram of workshop participants' opinions 
Table 3: System processes

\begin{tabular}{|c|l|c|}
\hline No & \multicolumn{1}{|c|}{ Process Name } & Covered Features \\
\hline P1 & Create/update user profile & $\mathrm{F} 1, \mathrm{~F} 16$ \\
\hline P2 & Manage course by instructor & $\mathrm{F} 10, \mathrm{~F} 11, \mathrm{~F} 13, \mathrm{~F} 16$ \\
\hline P3 & Manage a lesson by instructor & $\mathrm{F} 25$ \\
\hline P4 & Manage an announcement by instructor & $\mathrm{F} 15, \mathrm{~F} 16$ \\
\hline P5 & Enroll in a course, complete a lesson, and update the progress line & $\mathrm{F} 18, \mathrm{~F} 16$ \\
\hline P6 & Post a question and add a reply & $\mathrm{F} 6, \mathrm{~F} 29$ \\
\hline P7 & Approve an answer and add Award points/badges & $\mathrm{F} 6, \mathrm{~F} 20$ \\
\hline P8 & Complete a course, review/rate a course, and add Award points/badges \\
\hline P9 & Send private message to instructor or other learners & $\mathrm{F} 4$ \\
\hline P10 & $\begin{array}{l}\text { Post a new question in the discussion forum, like a reply, and add Award } \\
\text { points/badges }\end{array}$ & $\mathrm{F} 3, \mathrm{~F} 9, \mathrm{~F} 6, \mathrm{~F} 16$ \\
\hline P11 & Vote for offering a new course & $\mathrm{F} 24, \mathrm{~F} 16$ \\
\hline P12 & Add question to the questions bank & $\mathrm{F} 16, \mathrm{~F} 26$ \\
\hline
\end{tabular}

Figure 2 presents the process P2 ("Manage course by instructor") while other processes are described in Process Models (2020). For this process, once an instructor logs into the platform, he or she can create a new course. To create a new course, the instructor selects the name of the test (i.e., the courses are classified based on the type of test). Moreover, the instructor must set up some initial details such as the course title, the course description, the prerequisites, and the output expected from the course. After that, the admin will verify the course and change its status from "initial" to "approved." Afterwards, a notification will be sent to learners who are interested in the same type of test as the one that the instructor selected.

In order to implement our collaborative learning platform, the C\# language was used. Moreover, in order to develop and build the database, SQL Server Data Tools (SSDT) for Visual Studio was used. For the sake of brevity, the details of the implementation are omitted from this paper but they can be accessed through Platform Implementation (2019).

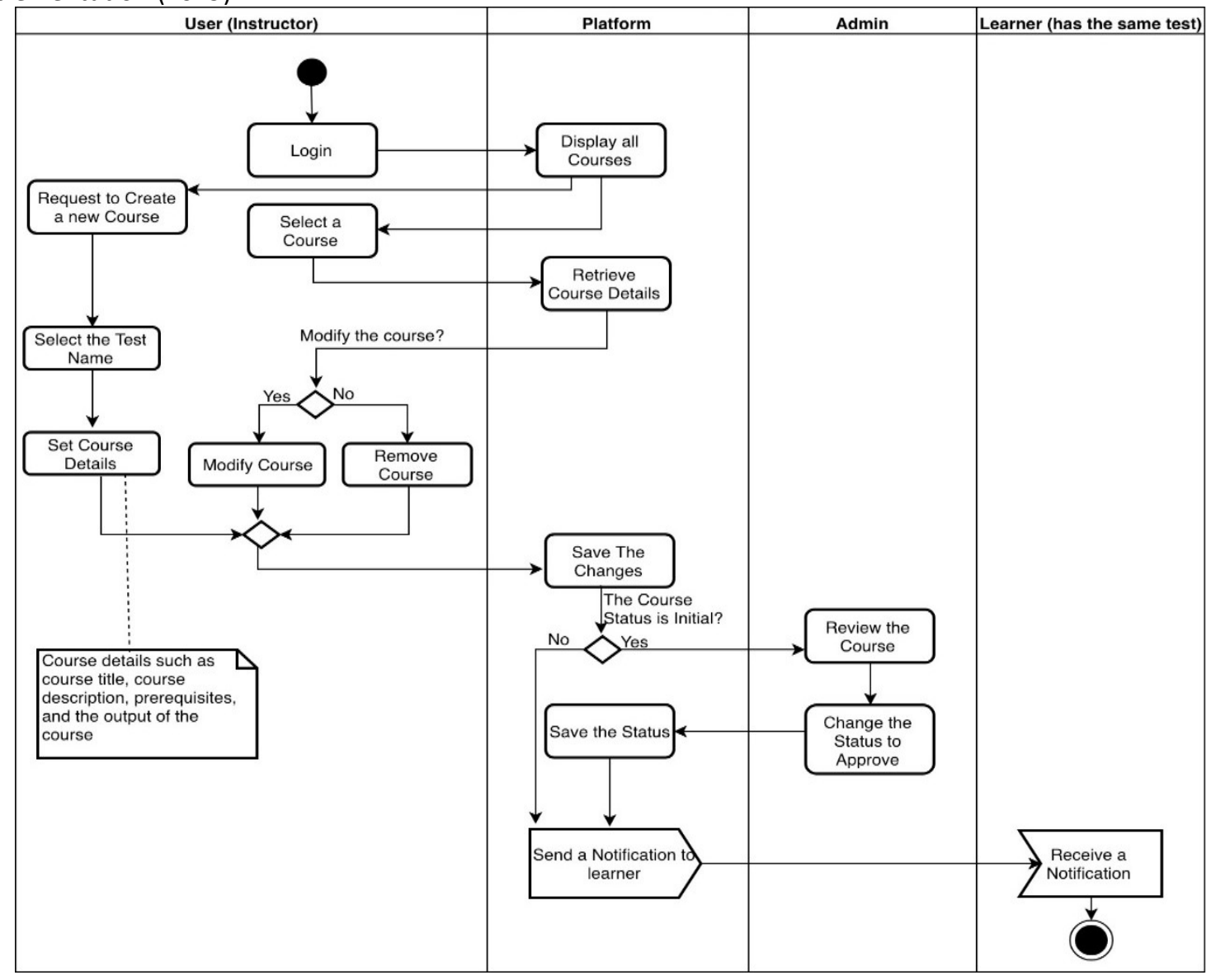

Figure 2: The process model for P2 (“Manage course by instructor") 


\section{Stage 4: Final Evaluation}

In this section, we evaluate the proposed collaborative platform for Qiyas tests. Two evaluation techniques have been used: in-depth interviews and an empirical study. They are presented below.

\subsection{In-Depth Interviews}

According to Boyce and Neale (2006), the in-depth interview is "a qualitative research technique that involves conducting intensive individual interviews with a small number of respondents to explore their perspectives on a particular idea, program, or situation." The primary advantage of using in-depth interviews is that interviewees are able to provide much more detailed information while they are in a more relaxed atmosphere. To conduct and design the interviews, the processes and guidelines described by Boyce and Neale (2006) were followed.

Two expert interviewees were selected. The first interviewee is an associate professor in computer education and instructional systems design. The second interviewee is a teacher who has a master's degree in educational technology.

The goal of the interviews was to assess the value of the provided functions from an educational perspective. The interviewees classified the features based on the general framework of evaluation for learning processes in computer-supported collaborative work (CSCL) presented by Pozzi et al. (2007). This framework was selected since it is a well-known framework for evaluating learning processes that use CSCL and since it is frequently used by other researchers (e.g. Wang, 2009; Persico, Manca and Pozzi, 2014; Björnsdóttir, Garfield and Everson, 2015).

This framework is based on a five-dimensional model. The first dimension is the participative dimension (P). It refers to taking part in an online collaborative experience and demonstrates that one is there, independently from any other action. The second dimension is the interactive dimension (I), which refers to the relationships that participants build during the learning processes (e.g., the interactivity between pairs). The third dimension is the social dimension (S), which is defined as the ability of participants in a community of inquiry to project themselves socially and emotionally as "real" people through the medium of communication being used. The fourth dimension is the cognitive dimension (C). This is defined as the extent to which learners are able to construct and confirm meaning through a sustained reflection and their discourse in a critical community of inquiry. The last dimension is the teaching dimension $(T)$. This refers to the design, facilitation, and direction of cognitive and social processes for the purpose of realizing personally meaningful and educationally worthwhile learning outcomes.

The interviewees believe the platform functions provide support for all of the five dimensions shown in Table 4. Four features provide support for the $(P)$ dimension, seven features provide support for the $(C)$ dimension, nine features provide support for the (I) dimension, and finally the $(\mathrm{S})$ and $(\mathrm{T})$ dimensions are supported by eight features each.

Both interviewees believe that the implemented platform will have a good impact on learners' performance since it will be a knowledge base for preparing and studying for the Qiyas tests. The interviewees believe from their own point of view that the most supportive features are F3, providing discussion forum (i.e., what we call "Qiyas community" in the implementation); F5, enroll in a course; and F26, providing a question bank.

Furthermore, the interviewees suggested that before the course enrollment (F5), all participants should have to read and agree on the terms of service. In addition, they mentioned that instructors should have the authority to ban or un-enroll students from their courses.

They also suggested creating a new role called a "moderator." This new role would be responsible for assisting the instructors in filtering or deleting inappropriate responses in the discussion threads. He or she could also be responsible for elevating the best posts or replies.

Concerning F6 (award points/badges to indicate active and collaborative learners), they believe that this feature will encourage learners to continue the learning process. Moreover, one of the interviewees suggested that instructors should have the ability to add a badge for a learner. 
From the interviews, we can conclude that the feedback was positive. The interviewees revealed good impressions about the implemented features on the platform.

Table 4: The classification of features based on the five-dimensional model

\begin{tabular}{|c|c|c|c|c|c|c|}
\hline No. & Feature & $\mathbf{P}$ & C & I & $\mathbf{S}$ & $\mathbf{T}$ \\
\hline F1 & Create user profile & $\checkmark$ & & & & \\
\hline F3 & Provide general discussion forum & $\checkmark$ & $\checkmark$ & $\checkmark$ & $\checkmark$ & \\
\hline F4 & Send private message to instructors and other learners & & & $\checkmark$ & $\checkmark$ & \\
\hline F5 & Enroll in a course & $\checkmark$ & $\checkmark$ & & & \\
\hline F6 & $\begin{array}{l}\text { Award points/badges to indicate active and collaborative } \\
\text { learners }\end{array}$ & & & & $\checkmark$ & $\checkmark$ \\
\hline F8 & Share course in social media & & & & $\checkmark$ & \\
\hline F9 & Like or follow other learners' posts & & & & $\checkmark$ & \\
\hline F10 & Classify courses & & & & & $\checkmark$ \\
\hline F11 & Create course by instructor & & & & & $\checkmark$ \\
\hline F13 & Display course details & & & & & $\checkmark$ \\
\hline F15 & Add Announcements & & & $\checkmark$ & & $\checkmark$ \\
\hline F16 & Receive notifications & $\checkmark$ & & & & \\
\hline F18 & Post a question and add a reply & & $\checkmark$ & $\checkmark$ & & $\checkmark$ \\
\hline $\mathrm{F} 20$ & Review and rate courses & & & $\checkmark$ & $\checkmark$ & \\
\hline F21 & Show learner progress in online learning process & & & $\checkmark$ & & \\
\hline $\mathrm{F} 22$ & Show number of participants in a course & & & & $\checkmark$ & \\
\hline F24 & Vote for offering a course & & & $\checkmark$ & $\checkmark$ & \\
\hline F25 & Add lessons into course & & $\checkmark$ & & & $\checkmark$ \\
\hline F26 & Provide Question Bank & & $\checkmark$ & $\checkmark$ & & \\
\hline $\mathrm{F} 27$ & Approve an answer & & $\checkmark$ & $\checkmark$ & & $\checkmark$ \\
\hline F28 & Complete a lesson & & $\checkmark$ & & & \\
\hline
\end{tabular}

\subsection{Empirical Evaluation}

In order to provide a deeper evaluation of the platform, an empirical study was carried out with three instructors and 26 learners. All of the instructors are teachers at the high school level. The participants have at least taken the GAT and SAAT tests. We guided the participants to focus on these two tests only while using the platform.

The participants were given two hours training in advance. We requested that they try all of the developed features. The experiment duration was 14 days. Table 5 shows the system usage at the end of the experiment.

After completing the experiment, we asked the participants to evaluate the value of the features using a fivepoint Likert scale. The instructors evaluated the features that related just to the teaching dimension (T) while the learners evaluated the features that related to the other dimensions. The features F6, F15, F18, F25, and F27 were evaluated by both types of participants since they include multiple dimensions. The instructors' evaluation is provided in Table 6 and Figure 3 while the learners' evaluation is provided in Table 7 and Figure 4. 
Table 5: System usage

\begin{tabular}{|c|c|c|}
\hline & Count & $\begin{array}{l}\text { Relevant } \\
\text { Features }\end{array}$ \\
\hline User profiles & 29 ( 3 instructors and 26 learners) & F1 \\
\hline Adding discussion threads & 12 & F3 \\
\hline Average posts per thread & 3.25 & F3 \\
\hline Private message to instructors and other learners & 43 & $\mathrm{~F} 4$ \\
\hline Enrolled learners in courses & $\begin{array}{l}26 \text { learners enrolled in courses, } 10 \\
\text { of them enrolled in two courses. }\end{array}$ & F5 \\
\hline number of badges obtained & 6 & F6 \\
\hline Sharing course in social media & $\begin{array}{l}22 \text { (14 shares in Twitter, } 5 \text { in } \\
\text { Facebook, } 3 \text { in Linkedln) }\end{array}$ & F8 \\
\hline Like or follow other learners' posts & 82 Likes and 16 Follows & F9 \\
\hline Number of course classifications & 2 & F10 \\
\hline Number of courses & 2 & F11 \\
\hline course details displayed & 2 & F13 \\
\hline Announcements & 11 & F15 \\
\hline Notifications & 270 & F16 \\
\hline Posted questions (under lessons) & 42 & F18 \\
\hline Posted replies (under lessons) & 71 & F18 \\
\hline Number of reviews for courses & 21 & F20 \\
\hline Number of ratings for all courses & 53 & F20 \\
\hline Number of learner progress bars created & 26 & F21 \\
\hline Number of participants completing courses & 36 (for 2 courses) & F22 \\
\hline Votes for offering a course (avg. per course) & 12 & F24 \\
\hline Number of lessons per course & 6 & $\mathrm{~F} 25$ \\
\hline Added questions in Question Bank & 32 & F26 \\
\hline Approved answers in Question Bank & 32 & F27 \\
\hline $\begin{array}{l}\text { Number of completed lessons (for all participants in } \\
\text { all courses) }\end{array}$ & 216 & F28 \\
\hline
\end{tabular}

It is clear from the data that most of the features received positive feedback. The instructors preferred features F11 and F25 the most followed by features F10 and F18. The learners believe that F5, F27, and F26 in order are the three most valuable features. We also calculated the scores for the five dimensions of the collaborative learning experience. For each dimension, we calculated the overall average for all of the features supporting the dimension. The results of the instructors' evaluation is only considered for the teaching dimension while the results of the learners' evaluation is considered for the other four dimensions. The results are shown in Table 8 and Figure 5. They show that the platform highly supports all of the dimensions. The results for all of the dimensions are relatively close to one another but the maximum values are the cognitive and participative dimensions ( $87.6 \%$ and $87.4 \%$ respectively) and the minimum value is associated with the social dimension (78.6\%). 
Table 6: Evaluation of the instructors

\begin{tabular}{|c|l|c|c|}
\hline No. & \multicolumn{1}{|c|}{ Feature } & Score Avg. & $\begin{array}{c}\text { Standard } \\
\text { Deviation }\end{array}$ \\
\hline F6 & Award points/badges to indicate active and collaborative learners & 4.33 & 0.58 \\
\hline F10 & Classify courses & 3.67 & 0.58 \\
\hline F11 & Create course by instructor & 5 & 0 \\
\hline F13 & Display course details & 3.67 & 0.58 \\
\hline F15 & Add Announcements & 4 & 1 \\
\hline F18 & Post a question and add a reply & 5.67 & 0.58 \\
\hline F25 & Add lessons into course & 4.33 & 0 \\
\hline F27 & Approve an answer & 5 & 0.58 \\
\hline
\end{tabular}

Table 7: Evaluation of the learners

\begin{tabular}{|c|l|c|c|}
\hline No. & \multicolumn{1}{|c|}{ Feature } & Score Avg. & $\begin{array}{c}\text { Standard } \\
\text { Deviation }\end{array}$ \\
\hline F1 & Create user profile & 3.92 & 1.13 \\
\hline F3 & Provide general discussion forum & 4.38 & 0.75 \\
\hline F4 & Send private message to instructors and other learners & 4.35 & 0.63 \\
\hline F5 & Enroll in a course & 4.81 & 0.4 \\
\hline F6 & Award points/badges to indicate active and collaborative learners & 3.96 & 0.92 \\
\hline F8 & Share course in social media & 3.73 & 0.78 \\
\hline F9 & Like or follow other learners' posts & 3.69 & 0.93 \\
\hline F15 & Add Announcements & 3.62 & 0.8 \\
\hline F16 & Receive notifications & 4.35 & 0.63 \\
\hline F18 & Post a question and add a reply & 4.19 & 0.69 \\
\hline F20 & Review and rate courses & 3.81 & 0.85 \\
\hline F21 & Show learner progress in online learning process & 3.62 & 0.94 \\
\hline F22 & Show number of participants in a course & 3.23 & 0.82 \\
\hline F24 & Vote for offering a course & 4.27 & 0.78 \\
\hline F25 & Add lessons into course & 4.42 & 0.76 \\
\hline F26 & Provide Question Bank & 4.54 & 0.71 \\
\hline F27 & Approve an answer & 4.73 & 0.45 \\
\hline F28 & Complete a lesson & 3.62 & 0.85 \\
\hline
\end{tabular}

Table 8: The results per dimension

\begin{tabular}{|c|c|c|c|c|}
\hline Dimension & No. of Votes & No. of Features & Overall Score Average & Percentage \\
\hline Participative & 26 & 4 & 4.37 & $87.4 \%$ \\
\hline Cognitive & 26 & 7 & 4.38 & $87.6 \%$ \\
\hline Interactive & 26 & 9 & 4.17 & $83.4 \%$ \\
\hline Social & 26 & 8 & 3.93 & $78.6 \%$ \\
\hline Teaching & 3 & 8 & 4.33 & $86.6 \%$ \\
\hline
\end{tabular}


The Electronic Journal of e-Learning Volume 19 Issue 32021

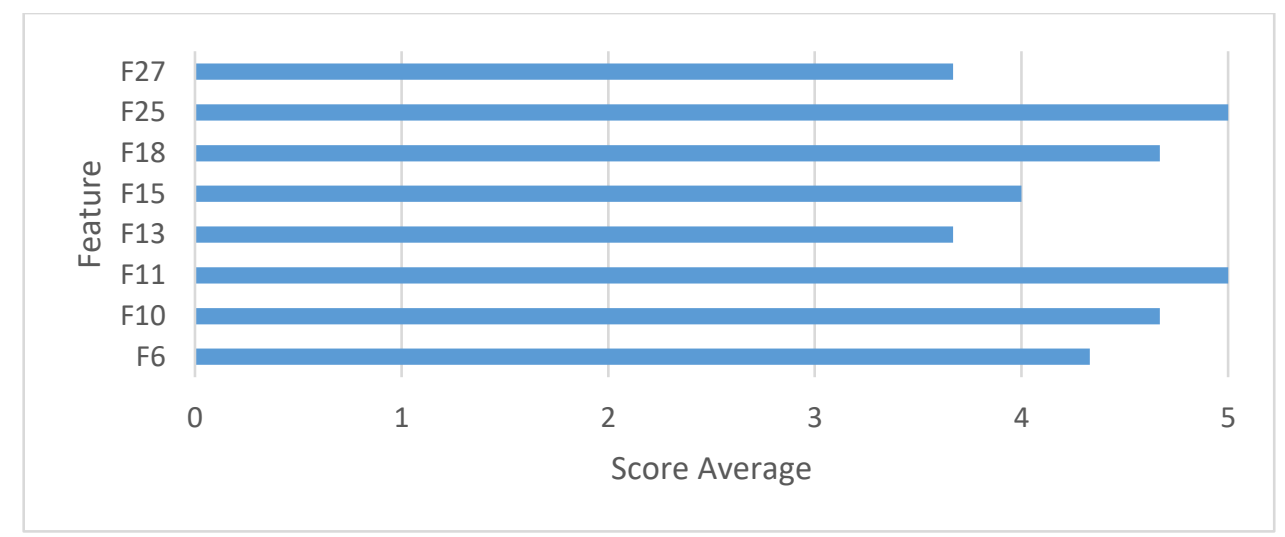

Figure 3: Histogram showing the evaluation of the instructors

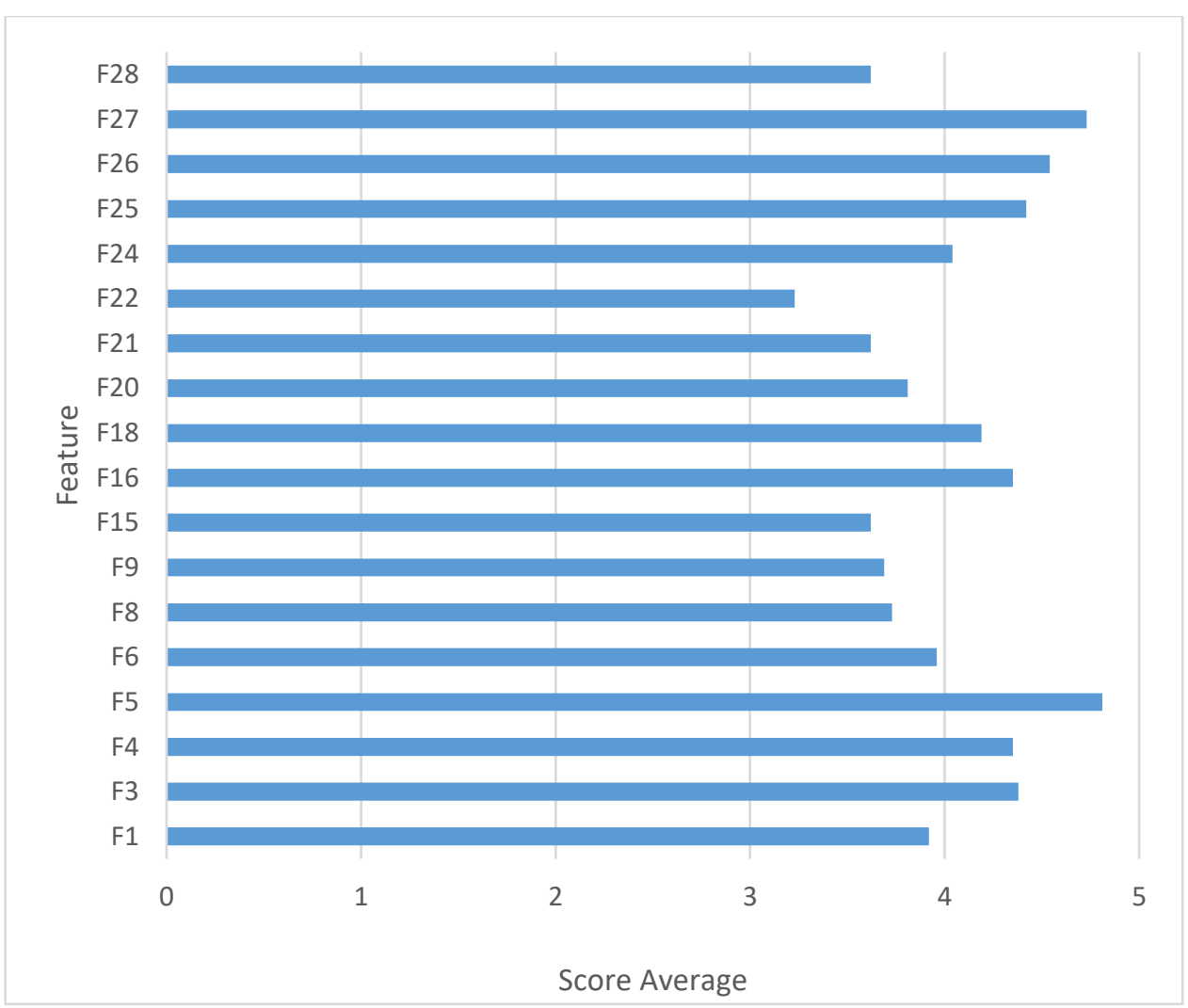

Figure 4: Histogram showing the evaluation of the learners

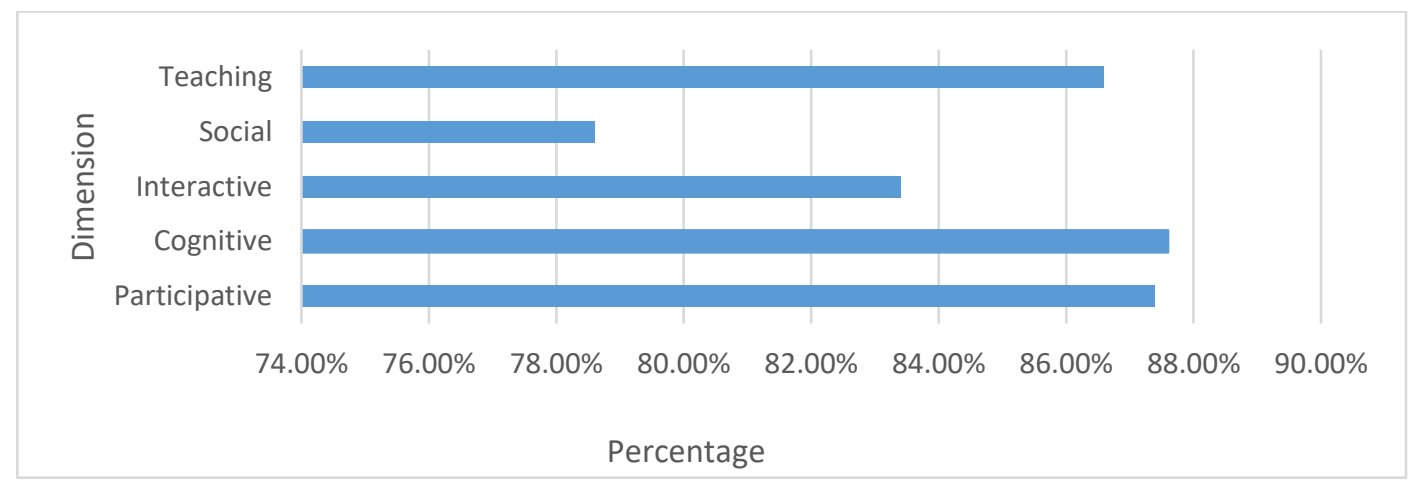

Figure 5: Histogram of the results per dimension 


\subsection{Further Discussion}

The proposed platform was designed for the Qiyas tests in particular. It includes 21 features support by the concept of collaborative learning. In comparison to the other platforms, the closest ones that support similar features are Open2Study, Udemy, and Skillshare. Open2Study supports 15 features that form $71 \%$ of the total features offered in our system, Udemy supports 14 features that form 67\%, and Skillshare supports 13 features that form $62 \%$. However, the quantity of the similar features on these platforms does not necessarily mean that they are able to provide the same amount of value. This is because most of the other platforms were developed using process logics different than the ones created for our platform. For instance, Open2Study was developed to be a mediator between established institutions (not individuals) in Australia and students for whom the institution could provide online courses, while our platform supports the registration of individual freelance instructors. Furthermore, all three of the platforms do not support the Arabic language. Therefore, it would not be possible currently to serve Qiyas users by providing courses in their first language. This also prevents one from making evaluations that provide comparisons between any of those platforms and our own platform. Nevertheless, all of the platforms discussed in this study were helpful for learning what kind of collaborative learning features could be potentially appropriate for our proposed platform, and this allowed us to offer a wider range of interesting options for participants who joined the two workshops discussed in Section 5.

\section{Conclusions}

In this paper, we have introduced an electronic collaborative learning environment for the Qiyas tests offered by the Saudi National Center for Assessment. This research was completed in four main stages: (1) by carrying out an intensive review of $30 \mathrm{CL}$ platforms in order to investigate the available features, (2) by conducting two workshops in order to evaluate the appropriateness of the features identified in Stage 1 and to investigate what other features could be appropriate for the Qiyas tests, (3) by developing a CL environment for the Qiyas tests that uses a total of 21 features, (4) and by evaluating the platform using two methods, in-depth interviews with experts and an empirical evaluation with instructors and learners.

The results show that the platform helps to support learners in the participative, cognitive, interactive, and social dimensions of the learning processes. The platform also helps instructors to promote the teaching experience.

We focused in this study on evaluating the usefulness of the features but we did not consider the usability of the system, which is left for future research. We also plan to develop and test some of the features requested by participants during the evaluation such as practicing a test, adding a search function, reporting inappropriate posts, uploading a CV in the instructor's profile, and setting dates for new announcements. A beta version of the platform will be published by the beginning of 2020 .

\section{References}

Al-Owidha, A., 2013. The Saudi standardized achievement admission test (SAAT): A study of construct-related validity evidence (Report No. TR038-2013). National Center for Assessment.

Al-Ozaizy, I., 2016. The impact of a training program on the performance of a sample of students in the General Abilities Test in the province of Mahd Althahab, International Interdisciplinary Journal of Education, 5(7), pp. 1-10.

Almajed, S., 2010. Impact of remote computer training in improving student's GAT marks, the7th Arabic Scientific Conference of Distinguished and Talented Students. Amman, 28-29 July 2010, Arabcgt.

Alnahdi, G. H., 2015. Aptitude tests and successful college students: the predictive validity of the general aptitude test (GAT) in Saudi Arabia, International Education Studies, 8(4), pp. 1-6.

Alyahya, S., 2020. Platform implementation. Available at: <https://www.dropbox.com/s/8mj78ttuc374loe/Platform Implementation.pdf?dl=0> [Accessed 1 May 2019].

Alyahya, S, 2020. Process Models. Available at: <https://www.dropbox.com/s/x972hvkg3hyopf3/Appendix.pdf?dl=0> [Accessed 1 May 2019].

Alyahya, S. and Alsayyari, M., 2020. Towards better crowdsourced software testing process, International Journal of Cooperative Information Systems, 29(1)., pp 1-36.

Bajammal, S., Zaini, R., Abuznadah, W., Al-Rukban, M., Aly, S., Boker, A., Al-Zalabani, A., Al-Omran, M., Al-Habib, A., AlSheikh, M., Al-Sultan, M., Fida, N., Alzahrani, K., Hamad, B., Al-Shehri, M., Abdulrahman, K.,, Al-Damegh, S., Al-Nozha and M., Donnon, T., 2008. The need for national medical licensing examination in Saudi Arabia, BMC Medical Education, 8(1), pp. 1-15.

Benbunan-Fich, R., Hiltz, S. R. and Harasim, L., 2004. The online interaction learning model: an integrated theoretical framework for learning network, In: S.R. Hiltz and R. Goldman (eds) Learning Together Online: Research on Asynchronous Learning Networks. London: Routledge pp. 19-37. 
Bennett, S., 2004. Supporting collaborative project teams using computer-based technologies. In: T. Roberts (ed) Online collaborative learning: theory and practice. London: Information Science Publishing, pp. 1-27.

Björnsdóttir, A., Garfield, J. and Everson, M., 2015. Evaluating two models of collaborative tests in an online introductory statistics course, Statistics Education Research Journal, 14(1), pp. 36-59.

Bow, H., Dattilo, Jonathan R., Jonas, A. and Lehmann, C., 2013. A crowdsourcing model for creating preclinical medical education study tools, Academic Medicine, 88(6), pp. 766-770.

Boyce, Carolyn, and Palena Neale, 2006. Conducting in-depth interviews: a guide for designing and conducting in-depth interviews. Watertown: Pathfinder.

Bruffee, K. A., 2006. Collaborative learning and the "Conversation of Mankind", College English, 46(7), pp. 635-652.

Cox, K., Niazi, M. and Verner, J., 2009. Empirical study of Sommerville and Sawyer's requirements engineering practices, IET Software, 3(5), pp. 339-355.

Ghazi, K., 2018. Reasons for variation in student achievement between high school tests and results of Qiyas center, International Journal of Educational and Psychological Sciences, 10(1).

Harris, J., 2001. Structuring internet-enriched learning spaces for understanding and action, Learning \& Leading with Technology, 28(4), pp. 50-55.

Hendrickson, P. B., 2012. Update on the education system of the Kingdom of Saudi Arabia, in American Association of Collegiate Registrars and Admissions Officers Annual Meeting, 4-7 Nov.2012 , Washington: AACRAO.

Johnson, D. W., Johnson, R.T., Stanne, M. B. and Garibaldi, A., 1990. Impact of group processing on achievement in cooperative groups, The Journal of Social Psychology, 130(4), pp. 507-516.

Kaki, S. M. and Alaskar, S. R., 2014. Mechanisms to improve the performance of the National Center for Measurement and Evaluation of Higher Education in the Kingdom of Saudi Arabia: challenges and ambitions, Journal of Educational and Psychological Sciences, 15(4), pp. 121-148.

Khoshaim, H. B., 2017. High School graduates' readiness for Tertiary Education in Saudi Arabia., International Journal of Instruction, 10(3), pp. 179-194.

Kimball, L., 2001, Managing distance learning: new challenges for faculty, In: R. Hazemi and S. Hailes (eds). The Digital University - Building a Learning Community. Berlin, Germany: Springer Verlag, pp. 25-38.

Lethbridge, T. C. and Laganière, R., 2004. Object-oriented software engineering: practical software development using UML and Java. Second ed. New York: McGraw-Hill Education.

Lin, C. S. and Kuo, M. S., 2005. Adaptive networked learning environments using learning objects, learner profiles and inhabited virtual learning worlds, Proceedings - 5th IEEE International Conference on Advanced Learning Technologies, 5-8 July 2005. Kaohsiung.

Lin, L., 2015. Investigating Chinese HE EFL Classrooms Using Collaborative Learning to Enhance Learning. Berlin: Springer.

Luo, H., 2013. An online collaborative learning mode in Management Information System experimental teaching. in Luo, $Q$. (ed) Advances in wireless networks and information systems. Berlin :Springer, pp. 351-357.

National Center for Assessment, 2019. Qiyas Statistics and Data. <www.qiyas.sa/en/Statistics-Data/Pages/Open-Data.aspx> [Accessed 1 May 2019].

Ngo, Chinch, 2018. The Best MOOC Platforms. Available at: <www.reviews.com/mooc-platforms> [Accessed: 1 May 2019].

Niazi, M., Wilson, D. and Zowghi, D., 2005. A maturity model for the implementation of software process improvement: an empirical study, Journal of Systems and Software, 74(2), pp. 155-172.

Persico, D., Manca, S. and Pozzi, F., 2014. Adapting the technology acceptance model to evaluate the innovative potential of e-learning systems, Computers in Human Behavior, 30 (Jan), pp. 614-622.

Pozzi, F., Manca, S., Persico, D., and Sarti L., 2007. A general framework for tracking and analysing learning processes in computer-supported collaborative learning environments, Education and Teaching International, 44(2), pp. 169-179.

Rainer, A. and Hall, T., 2002. Key success factors for implementing software process improvement: a maturity-based analysis', Journal of Systems and Software, 62(2), pp. 71-84.

Smith, L., MacGregor, J.T., Smith, B.L. and MacGregor, J.T., 1992. What is collaborative learning?, Collaborative Learning: A Sourcebook for Higher Education, Pennsylvania State University, PA: National Center on Postsecondary Teaching, Learning, and Assessment., pp. 10-30.

Sulphey, M., AlKahtani, N. and Syed, A., 2018. Relationship between admission grades and academic achievement, Entrepreneurship and Sustainability Issues, 5(3), pp. 648-658.

Thompson, L. and Ku, H.Y., 2006. A case study of online collaborative learning, Quarterly Review of Distance Education, 7(4), pp. 361-375.

Tiberius, R. and Silver, I., 2001. Guidelines for conducting workshops and seminars that actively engage participants. Toronto: Department of Psychiatry, University of Toronto.

Wang, Q., 2009. Design and evaluation of a collaborative learning environment, Computers and Education, 53(4), pp. $1138-1146$.

Zahirović, A., Despotović-Zrakić, M., Labus, A,. Bogdanović, Z., Barać, D., 2019. Fostering students' participation in creating educational content through crowdsourcing, Interactive Learning Environments, 27(1), pp. 72-85.

Zhu, C., 2012. Student satisfaction, performance, and knowledge construction in online, Journal of Educational Technology Society, 15(1), pp. 127-136. 